\title{
O USO DO PADLET PARA OS LETRAMENTOS DO ESTUDANTE
}

\author{
THE USE OF PADLET FOR STUDENT LETTERING
}

\begin{abstract}
Daniela Rebello Pereira Sylvestre ${ }^{1}$
RESUMO: A preocupação básica deste estudo é refletir sobre o uso do Padlet para os letramentos dos estudantes nas aulas de Língua Portuguesa, visto que é inquestionável a inserção dos estudantes no mundo da cibercultura. Para o desenvolvimento deste tema, as seguintes perguntas nortearam o trabalho: Como o professor pode melhorar a escrita e leitura do estudante nesse contexto da cibercultura em que vivemos? e $\mathrm{O}$ uso do Padlet pode contribuir para o letramento do estudante na disciplina de Língua Portuguesa? Este artigo tem como objetivo analisar a importância da apropriação de novas tecnologias digitais pelo professor para uma melhor qualidade no processo de construção do conhecimento dos estudantes, procurando motivá-los e envolvê-los através de ambientes virtuais de aprendizagem. Utilizou-se como recurso metodológico uma pesquisa bibliográfica considerando as contribuições de autores como ALONSO, GALLEGO e HONEY (2002), GARDNER (1998), RELVAS (2018), LÉVY (1999) e SOARES (2004) entre outros, procurando enfatizar a importância do conhecimento do professor do processo de construção de conhecimento do estudante, bem como a necessidade dele assumir seu papel social de mediador no processo ensino-aprendizagem através do uso consciente dos ambientes virtuais de aprendizagem, especificamente o Padlet. Concluiu-se a importância de ter um professor mediador, nesse recurso do Padlet para garantir os benefícios do uso do mesmo para os letramentos do estudante.
\end{abstract}

Palavras-chave: TIC - Tecnologia da Informação e Comunicação. AVA- Ambiente Virtual de Aprendizagem. Cibercultura. Padlet. Letramentos.

ABSTRACT: The basic concern of this study is to reflect on the use of Padlet for students' literacies in Portuguese Language classes, since it is unquestionable the insertion of students in the world of cyberculture. For the development of this theme, the following questions guided the work: How can the teacher improve the student's writing and reading in this context of cyberculture in which we live? and Can the use of Padlet contribute to student literacy in the Portuguese language discipline? This article aims to analyze the importance of the appropriation of new digital technologies by the teacher for a better quality in the process of building students' knowledge, seeking to motivate and involve them through virtual learning environments. A bibliographic research was used as a methodological resource considering the contributions of authors such as ALONSO, GALLEGO and HONEY (2002), GARDNER (1998), RELVAS (2018), LÉVY (1999) and SOARES (2004) among others, trying to emphasize the importance the teacher's knowledge of the student's knowledge-building process, as well as the need for him to assume his social role as mediator in the teaching-learning process through the conscious use of virtual learning

\footnotetext{
1 Graduada em Letras pela Universidade Estácio de Sá, pós-graduação Lato Sensu em Leitura e Produção Textual pela Universidade Estácio de Sá, especialista em Neuropsicopedagogia pela Universidade Cândido Mendes, professora de Língua Portuguesa e Literatura, servidora pública estadual do Rio de JaneiroSEEDUC- doc 2, servidora pública municipal de Magé-SMEC- doc, docente na Educação Básica de Língua Portuguesa e Literatura, e pesquisadora em EAD- TIC e Linguagens comunicacionais. Email:profadanielasylvestre@gmail.com.
} 
environments, specifically the Padlet. We concluded the importance of having a mediating teacher, in this resource of the Padlet to guarantee the benefits of using it for the student's literacies.

Keywords: ICT - Information and Communication Technology. AVA- Virtual Learning Environment. Cyberculture. Padlet. Literacies.

\section{INTRODUÇÃO}

O presente trabalho tem como tema a utilização do Padlet nas aulas de Língua Portuguesa a fim de que os estudantes desenvolvam os seus letramentos, visto que é inquestionável a inserção dos estudantes no mundo da cibercultura.

Para o desenvolvimento deste tema, as seguintes perguntas nortearam o trabalho:

- Como o professor pode melhorar a escrita e leitura do estudante nesse contexto da cibercultura em que vivemos?

- O uso do Padlet pode contribuir para o letramento do estudante na disciplina de Língua Portuguesa?

Padlet é um aplicativo de Internet que permite que as pessoas expressem, facilmente, seus pensamentos sobre um tema comum. Ele funciona como uma folha de papel on-line onde as pessoas podem colocar qualquer conteúdo (por exemplo, imagens, vídeos, documentos de texto) em qualquer lugar da página, junto com qualquer dispositivo.

Considera-se o letramento segundo a definição da autora Magda Soares, em que a criança mais do que alfabetizada, domina as habilidades de leitura e de escrita necessárias para uma participação efetiva e competente nas práticas sociais e profissionais que envolvem a língua escrita.

Os estudantes aprendem quando estão motivados, esse processo ocorre no interior do sujeito, em íntima relação de troca com o seu meio, principalmente, entre seus professores e colegas de acordo com a pesquisadora Marta Relvas. Estando os estudantes, atualmente, vivendo no contexto da cibercultura, cabe ao professor, mediador desse processo de ensino-aprendizagem, utilizar conscientemente dos recursos oferecidos pelo ambiente virtual de aprendizagem, especialmente do Padlet para estimular a motivação dos seus aprendentes, através de uma aprendizagem colaborativa assíncrona e/ ou síncrona.

Logo, o objetivo primordial deste estudo é, pois, demonstrar como o Padlet pode contribuir para os letramentos de estudantes nas aulas de Língua Portuguesa.

Para alcançar o objetivo proposto, utilizou-se como recurso metodológico, a pesquisa bibliográfica, realizada a partir da análise pormenorizada de materiais já publicados na literatura e artigos científicos divulgados no meio eletrônico. 
O texto final foi fundamentado nas ideias e concepções de autores como: ALONSO, GALLEGO e HONEY (2002), GARDNER (1995), RELVAS (2018), LÉVY (1999) e SOARES (2004).

A sociedade atual é compreendida em um contexto de Cibercultura, em que as competências tecnológicas podem ser desenvolvidas diretamente através da interação do sujeito com o objeto digital. O ciberespaço se configura em uma de suas vertentes mais atuantes e controversas, conforme nos lembra Lévy (1999):

\footnotetext{
Internet é um espaço de comunicação propriamente surrealista, do qual nada é excluído, nem o bem, nem o mal, nem suas múltiplas definições, nem discussões... A internet encarna a presença da humanidade a ela própria, já que todas as culturas, todas as disciplinas, todas as paixões aí se entrelaçam. Já que tudo é possível, ela manifesta a conexão do homem com a sua própria essência, que é a aspiração à liberdade. (LÉVY, 1999, p. 85)
}

A cibercultura vem proporcionando novas possibilidades de interação e aprendizagem com a mediação do ciberespaço. Assim, é inegável a reorganização do projeto educacional, que contemple as possibilidades do hipertexto e da interatividade nesses novos espaços de aprendizagem.

O ensino on-line começou com aumento de aplicativos que possibilitam o fácil e rápido acesso de informação quando o aluno está em circunstâncias em que não há presença física do professor. Ensino on-line revela, inclusive, o potencial de recursos de curta informação como um canal de comunicação eficaz com sujeitos em espaços digitais.

Ambiente virtual de aprendizagem (AVA), também conhecidos como e-learning ou plataformas LMS Learning management systems, é compreendido como espaço social e digital e pode ser colaborativo. Possibilita o compartilhamento de diferentes mídias, software, arquivos, linguagens como HTML, 3 D Max e outros. No entanto, os ambientes virtuais de aprendizagens não prescindem do professor, mas, preferencialmente, deve possibilitar o monitoramento e acompanhamento técnico e pedagógico do estudo dos alunos.

O EAD é uma modalidade de ensino em que prevalece a autoaprendizagem, o estudante recebe o material didático do curso com instruções, conteúdos e atividades, para realizá-las individualmente e virtualmente, com uma tutoria. $\mathrm{O}$ material didático é o centro do processo, o aluno realiza as atividades no seu tempo, desenvolvendo a sua autonomia.

Com o AVA, além da autoaprendizagem, esses ambientes permitem a interatividade e a aprendizagem colaborativa, através de processos de comunicação síncronas e assíncronas (fóruns de discussão, chats e padlets, a ferramenta analisada neste trabalho), assim, o estudante aprende com material didático, com tutores e com outros estudantes. Isso potencializa a democratização da informação, da aprendizagem entre indivíduos geograficamente dispersos. 
Padlet é um aplicativo de Internet que permite que as pessoas expressem, facilmente, seus pensamentos sobre um tema comum. Ele funciona como uma folha de papel on-line onde as pessoas podem colocar qualquer conteúdo (por exemplo, imagens, vídeos, documentos de texto) em qualquer lugar da página, junto com qualquer dispositivo.

Apresentado como solução para problemas educacionais, o EAD converte-se em domínio no qual se imiscuem interesses políticos e econômicos de caráter restrito. $\mathrm{Na}$ atual conjuntura, a prevalência de interesses privados instrumentaliza a educação e distorce projetos de publicização do ensino a distância.

O discurso em prol da democratização do ensino, das oportunidades de acesso ao sistema educacional e da justiça social mascara o sentido de investimentos privados. É empregado como expediente ideológico que viabiliza a aceitação e a expansão do ensino pago. A rede privada ampliase mediante programas de ensino a distância.

Submetido ao controle privado, ao invés de proporcionar o acesso indiscriminado à educação, o EAD tende a refinar a exclusão social.

Em meados dos anos 1980, é que se deu a invenção do termo letramento, no Brasil, que de acordo com a Magda Soares é muito mais do que o indivíduo decodificar as letras, sabendo ler e escrever, isto é a alfabetização. O letramento é desenvolvimento de habilidades de uso desse sistema em atividades de leitura e escrita, nas práticas sociais que envolvem a língua escrita. Para ela, não são processos independentes, mas interdependentes, e indissociáveis, porém, são processos de natureza fundamentalmente diferentes, envolvendo conhecimentos, habilidades e competências específicos, que implicam formas de aprendizagem diferenciadas e, consequentemente, procedimentos diferenciados de ensino.

É necessário reconhecer as muitas facetas de um e de outro processo e, por sua vez, a diversidade de métodos e procedimentos para o ensino de um e de outro. Visto isto, há de se considerar as características de cada grupo de estudantes, e até de cada estudante, exigir formas diferenciadas de ação pedagógica.

Diante desse cenário da cibercultura, em pesquisas mais recentes a autora Magda Soares (2002) propõe o uso "do letramentos", no plural, para enfatizar a ideia de que diferentes tecnologias de escrita geram diferentes estados ou condições naqueles que fazem uso dessas tecnologias em suas práticas de leitura e escrita.

Como formação humana, o que se busca é garantir ao adolescente, ao jovem e ao adulto trabalhador o direito a uma formação completa para a leitura do mundo e para a atuação como cidadão pertencente a um país, integrado dignamente à sua sociedade política. Formação que, neste sentido, supõe a compreensão das relações sociais subjacentes a todos os fenômenos (CIAVATTA, 2005, p. 85 apud RAMOS, Marise) 
Segundo a pesquisadora Marta Relvas (2018) a aprendizagem é um fenômeno extremamente complexo, envolvendo aspectos cognitivos, emocionais, orgânicos, psicológicos, sociais e culturais. Para aprender, a pessoa precisa desenvolver aptidões e conhecimentos e transferir estes para novas situações.

Para ela, aprendizagem é desencadeada a partir de motivação. Portanto, o estudante tem que desejar aprender, mas, o processo é uma relação de troca com o meio, principalmente entre professor e aluno. Relvas (2018) define o ato de aprender com um "ato de plasticidade cerebral”, modulado por fatores intrínsecos (genéticos) e extrínsecos (experiências).

Atualmente, é notória a relação do ser humano com tecnologias como computadores e smartphones com internet, assim, é incoerente acreditar numa educação tradicional presencial, sem a mediação das TICs e dos AVAs.

A teoria das inteligências múltiplas do pesquisador Gardner já é aceita e empregada por inúmeros cientistas e teóricos da educação. Segundo ele, há as seguintes inteligências: linguística, lógico-matemática, espacial, musical, corporal, cinestésica, interpessoal, intrapessoal, naturalista e existencial.

Importante destacar que o próprio Gardner ensina sobre a pouca importância na delimitação quanto ao número de inteligências, ou seja, a quantidade de inteligências é menos importante que entender a existência de uma multiplicidade de inteligências. Sobre este tema "não há e jamais haverá uma lista única, irrefutável e universalmente aceita de inteligências humanas” (GARDNER, 1995, p. 45) pois a inteligência não existe como verificável fisicamente, é uma construção que se manifesta pelos comportamentos.

Alonso, Gallego e Honey (2002), em seus estudos, identificaram quatro estilos de aprendizagem: o ativo, o reflexivo, o teórico e o pragmático. As pessoas em que predomina o estilo ativo de aprendizagem gostam de experiências novas e, por isso, seus dias são consumidos por diversas atividades. Já as pessoas com estilo reflexivo analisam suas experiências sob diferentes perspectivas, observando a atuação dos demais, antes de chegar a alguma conclusão. Antes de fazer algo, essas pessoas consideram todas as possíveis alternativas. Os estudantes com estilo teórico trabalham mais com o racional e por isso são mais objetivos; são profundos em seus pensamentos e em suas teorias; são críticos, metódicos, lógicos. Já as pessoas pragmáticas gostam de aplicar na prática suas ideias e são impacientes com pessoas que se demoram na teorização.

Diante dessa multiplicidade de habilidades predominantes nos estudantes, deve haver uma mudança na metodologia de ensino-aprendizagem, no momento em que se acredita que várias inteligências devem ser estimuladas e desenvolvidas e que os alunos aprendem de forma diferente, o professor deve preparar sua aula valendo-se de diferentes mecanismos de aprendizagem de forma 
a contemplar ao máximo os estímulos. Dessa forma, potencializa a aprendizagem e respeita as mais variadas inteligências. O uso de AVAs, especificamente do Padlet para o aprimoramento do letramento, faz-se uma ferramenta útil e benéfica, conforme veremos adiante.

O Brasil é um país com grande diversidade regional, cultural e com grandes desigualdades sociais; portanto, não é possível pensar em um modelo único para incorporação de recursos tecnológicos na educação. É necessário pensar em propostas que atendam aos interesses e necessidades de cada região ou comunidade.

Em nosso país, existe uma educação dualística porque não há unicidade entre as dimensões científica, tecnológica e cultural. O Brasil é um Estado capitalista de terceiro mundo, onde as condições básicas de saúde, saneamento, segurança pública e educação não são acessíveis a todos, uma educação que privilegie a leitura como forma de construção de um cidadão crítico e consciente de seu papel na sociedade, é de extrema relevância.

O estudante deve ser compreendido como um cidadão, sua formação não deve e não pode ser somente para o trabalho enquanto empregado. Sua educação deve contemplar as dimensões científica, tecnológica e cultural. E através do letramento, esse estudante, terá maiores chances de se formar um sujeito emancipado, independentemente de sua origem socioeconômica.

Nesse sentido, o professor deve ser facilitador e orientador no processo da aprendizagem. Assim:

Este deve usar de vários recursos para ampliar a habilidade de escrita nos alunos, sendo assim, é necessária conscientização do seu papel, deve haver preparo, estudo, dedicação e, algumas vezes, mudança de estratégia para se alcançar o objetivo. Se o foco estiver além da gramática, deve se dar atenção à compreensão dos textos, à clareza e precisão da linguagem. Buscar nas produções o máximo de qualidade possível. (SILVA e DUARTE, 2018, p. 5)

As tecnologias têm modificado significativamente as relações do homem com o mundo. Em toda parte, há alguma ferramenta digital e a escola deve apropriar-se conscientemente desses recursos, em especial dos AVA.

A simples presença das TICs na escola não contribui e nem garante a melhoria da qualidade do ensino-aprendizagem, pois a aparente modernidade pode mascarar um ensino conteudista, tradicional, baseado na memorização e recepção de informações. Porém se bem utilizadas, as tecnologias dinamizam o ensino como uma experiência proveitosa tanto para aluno quanto para professor.

É inegável que os computadores e smartphones têm sido mediadores de leitura e escrita. Neste sentido, a experiência em sala de aula para melhorar a argumentação em textos dissertativos acelera, e muito, o processo de ensino e aprendizagem, com projetos interativos que usem a rede eletrônica. 
A narrativa digital, também conhecida por digital storytelling, define-se como sendo uma ferramenta digital que apoia os alunos na criação de trabalhos escolares (estórias). Esta ferramenta é bastante poderosa, interativa e muitas vezes presente em formato atraente e emocionalmente envolvente. Pode-se também definir como sendo um processo pelo qual diversas pessoas partilham a sua história de vida elaborada com criatividade (WIKIPÉDIA, online).

Como ferramenta para desenvolver a produção textual e consequente letramento dos alunos, sugere-se o uso do padlet.

Ferramentas como o Padlet, que apresentam características colaborativas, permitem a interação dos sujeitos difundindo ideias, cultura, democratizando as informações e aprendendo em um contexto diferente do presencial, ou seja, da tradicional sala de aula. (SILVA e LIMA, 2018, p. 83)

O uso desse aplicativo Padlet favorece a interação e comunicação, cooperando para o desenvolvimento do processo de ensino-aprendizagem e o letramento, pautado na linguagem do hipertexto, pois os materiais disponibilizados possibilitam a navegação do aluno por diferentes hiperlinks. Conforme Carlotto, a "hipertextualidade é a possibilidade de trânsito dos sujeitos diante dos links da internet." (CARLOTTO, 2003, p. 94). Quanto mais se promove ambientes virtuais de aprendizagens hiper linkadas, mais se promove interação entre sujeito e informação, não há conteúdo fechado, nem planejamento rígido, tudo está por vir e ser construído, de acordo com a navegação de cada aluno.

A escrita colaborativa por meio do sistema padlet proporciona o aprimoramento da escrita dos alunos com as postagens de suas produções textuais sem que se sintam pressionados, atribuindo a cada tópico acrescido, um sentido, de forma contextualizada. Sendo o padlet uma ferramenta na qual todos podem acessar e fazer comentários, os alunos buscam minimizar seus erros e enriquecer suas produções com links, fotos, ilustrações e sons.

A sugestão é que o professor utilize como metodologia, atividades de aplicação de textos para a leitura e pesquisas sobre temáticas sociais, discussões sobre os temas, guiadas por ele, em sala de aula, observando o aprofundamento da temática e o entendimento individual de cada estudante. Seguida de produções de argumentos que defenda o ponto de vista individual de cada aluno e orientações ortográficas e de pontuação. Diante disso, abre-se um espaço no ambiente colaborativo para que cada aluno coloque seu ponto de vista sobre determinadas temáticas. Nesse ambiente de produção, os alunos podem interagir com o texto dos colegas, motivando-se a produzir de forma colaborativa, e individual sendo acompanhados, alunos e professor em tempo real, mediante a utilização de smartphones ou de computadores. 
A linha de raciocínio no uso do padlet se aproxima do modo de utilização da enciclopédia livre - wikipedia, que se aproxima da ferramenta wiki, ferramenta utilizada na plataforma moodle, locus de desenvolvimento da modalidade de educação a distância.

Logo, conclui-se que a cibercultura, através dos AVAs, especialmente, do Padlet, potencializa a democratização da informação, da comunicação e da aprendizagem entre indivíduos geograficamente dispersos. O Padlet é uma interface de comunicação síncrona e assíncrona, que amplia a prática pedagógica presencial, tendo a educação on-line colaborativa como diferencial, motivando os estudantes a irem além da autoaprendizagem. Permite ao professor, tornar suas aulas mais prazerosas, valorizando as inúmeras inteligências, segundo Gardner (1995) e respeitando os diferentes estilos de aprendizagem, conforme Alonso, Gallego e Honey (2002).

Dessa forma constatou-se que com o uso do Padlet, o professor desenvolve os diversos letramentos como sugere Soares (2004), já que o estudante colocará em ação diversas habilidades de leitura e escrita, através de sua mediação consciente para uma participação efetiva e competente nas diversas práticas sociais que envolvem a Língua Portuguesa.

Sendo assim, o professor, ciente de seu papel de estimulador e mediador entre aluno e conhecimento, segundo Relvas (2018), deve procurar criar condições favoráveis para que o estudante tenha motivos de ação para apropriar-se do conhecimento socialmente acumulado, tornando-se letrado. O Padlet conforme todo o exposto, mostrou-se uma ferramenta digital facilitadora dessa responsabilidade do professor no contexto da cibercultura na qual vivemos.

\section{REFERÊNCIAS BIBLIOGRÁFICAS:}

ALONSO, C. M.; GALLEGO, D. J.; HONEY, P. Los estilos de aprendizaje: procedimientos de diagnóstico y mejora. Madrid: Mensajero, 2002.

CARLOTTO, Fabiane - Internet: oceanos de informação. In FERREIRA, Lenira Weil (org.) Leituras, significações plurais: educação e mídia: o visível, o ilusório, a imagem. Porto Alegre, RS. editora EDIPUCRS, 2003.

CIAVATTA, Maria. Ensino Integrado, a Politecnia e a Educação Omnilateral: por que lutamos? Revista Trabalho \& Educação, v. 23, n. I, p. 187-205, 2014. Disponível em: O ENSINO INTEGRADO, A POLITECNIA E A EDUCAÇÃO OMNILATERAL. POR QUE LUTAMOS? / The integrated education, the polytechnic and the omnilateral education. Why do we fight? | Trabalho \& Educação - ISSN 1516-9537 / e-ISSN 2238-037X Acesso em 23 maio 2020.

GARDNER, Howard. Inteligências Múltiplas - A teoria na Prática. Porto Alegre: Editora Artmed, I995.

LÉVY, Pierry. Cibercultura. São Paulo: Editora 34, 1999. 
NARRATIVA DIGITAL. In: WIKIPÉDIA, a enciclopédia livre. Flórida: Wikimedia Foundation, 2020. Disponível em: https://pt.wikipedia.org/w/index.php?title $=$ Narrati $=58648836$. Acesso em: 30 jun. 2020.

OLIVEIRA, F. A.; SANTOS, A. M. S. DOS. Construção do Conhecimento na Modalidade de Educação a Distância: Descortinando as Potencialidades da EaD no Brasil. EaD em Foco, v. Io, n. I, p. 26, 31, jan. 2020.

RAMOS, M., Schäffer, A. M., \& Viana, H. O AVA e os estilos de aprendizagem no contexto de educação a distância. Acta científica, v. 26, n. 2, p. 19-30, junho, 2018. Disponível em: O AVA E OS ESTILOS DE APRENDIZAGEM NO CONTEXTO DE EDUCAÇÃO A DISTÂNCIA | Acta Científica Acesso em 25 de junho de 2020.

RAMOS, Marise Nogueira. História e política da educação profissional. $\mathrm{I}^{\mathrm{a}}$ edição. Coleção Formação Pedagógica. Volume V. Curitiba: Instituto Federal do Paraná, 2014. Disponível em: http://curitiba.ifpr.edu.br/wp-content/uploads/2016/o5/Hist\%C3\%B3ria-e-pol\%C3\%ADtica-daeduca\% $\mathrm{C}_{3} \% \mathrm{~A}_{7} \% \mathrm{C}_{3} \% \mathrm{~A}_{30}$-profissional.pdf Acesso em 22 abril 2020.

Io- RELVAS, Marta Pires. Neurociência e educação: potencialidades dos gêneros humanos na sala de aula. 3. ed. Rio de Janeiro: WAK editora, 2018.

SANTOS, Edméa. Pesquisa-formação na cibercultura, Teresina: EDUFPI, 2019.

SILVA, José Washington Vieira; DUARTE, Madileide de Oliveira. O uso do Padlet na produção textual no ensino médio/normal. In: Congresso Internacional de educação e tecnologias, Encontro de pesquisadores de educação a distância. 26 de junho a I3 de julho, 2018, São Paulo: UFSCar, 2018, p.I-II. Disponível em: O USO DO SISTEMA PADLET NA PRODUÇÃO TEXTUAL NO ENSINO MÉDIO/NORMAL. Acesso em 2I de maio de 2020.

SILVA, Patrícia Grasel da; LIMA, Dione Sousa de. Padlet como ambiente virtual de aprendizagem na formação de profissionais da educação. Revista Novas Tecnologias na Educação, v. I6, n.I, p. 83 a 93, julho, 20I8. Disponível em: PADLET COMO AMBIENTE VIRTUAL DE APRENDIZAGEM NA FORMAÇÃO DE PROFISSIONAIS DA EDUCAÇÃO | Grasel da Silva $\mid$ RENOTE Acesso em 20 de maio de 2020.

SOARES, Magda. Letramento e alfabetização: as muitas facetas. In: GT Alfabetização, Leitura e Escrita, durante a 26- Reunião Anual da ANPEd, 5 a 8 de outubro de 2003, Minas Gerais: Revista Brasileira de Educação, n. 25, Jan /Fev / Mar / Abr 2004. Disponível em: Letramento e alfabetização: as muitas facetas* Acesso em 25 de junho de 2020 .

SOARES, Magda. Letramento: um tema em três gêneros, 3. ed. - Belo Horizonte: Autêntica Editora, 2009.

SOARES, Magda. Novas práticas e leitura e escrita: letramento na cibercultura. Educ. Soc., Campinas, vol. 23, n. 8I, p. I43-r6o, dez. 2002. Disponível em NOVAS PRÁTICAS DE LEITURA E ESCRITA: LETRAMENTO NA CIBERCULTURA Acesso em 27 de junho de 2020. 